November 1. The intumescence extends below the nipple, reaches into the axilla, and ascends above the clavicle. A distinct fluctuation can be felt; no apparent increased difficulty of breathing or aggravation of cough; can lie upon the affected side, but appears most easy when nursed in the erect position.

3. The swelling has attained the size of a large orange, pointed with a blush of redness on its surface. The parents object to its being punctured.

5. Permission was obtained to make an opening. Even at this juncture the symptoms were not supposed to have any connection with the thoracic cavity. A puncture having been made at the most prominent part, not less than fourteen ounces of well digested pus readily followed, when the little patient became suddenly seized with the most distressing dyspnœa and suffocating cough, which continued several minutes, and seemed, for the time, to threaten death. Concurrent with every respiration a rush of blood of a bright scarlet color, mixed with bubbles of air, escaped from the wound. On applying the ear to the chest, a deep cavernous rattle could be heard, and a very singular movement of the parietes of the affected side of the thorax was observed. On every attempt to breathe, which was performed by a kind of convulsive effort, I could compare the movement to nothing better than the flapping action of the valve of a common pair of bellows. This continued until the puncture was closed, and a linen roller passed several times round the chest. No doubt any longer existed as to the exact nature of the case, masked as it had been in its first stages by an almost total absence of symptoms indicative of any acute pulmonary affection. The patient was ordered to bed, the shoulders to be kept elevated, and strict quietude enjoined. Diet to consist of light animal broth.

8. Considerable relief followed the puncture, which was now repeated, and about two ounces of pus evacuated, mixed with frothy blood; the same flapping action of the parietes of the chest followed, together with the suffocating cough and dyspnœa, but marked with a less degree of intensity. On closing the aperture and reapplying the bandage, these symptoms subsided, and the patient was again placed quietly in bed.

At the end of two days the puncture was repeated; a small quantity of pus followed; the flapping action and cough ceased. From this time only a slight exu. dation of sero-purulent fluid took place from the opening, and the fulness had nearly disappeared. The health gradually improved. At the end of three weeks from the last time the abscess was opened, the patient was enabled to take exercise in the open air, and gradual restoration to health took place. The chest, when examined, at this time elicited rather a dull sound on the diseased side, and the respiratory murmur was less perfectly developed. The respiratory functions, however, in all other respects appeared to have but slightly suffered.

Abscess of the lung, as a product of simple phlogosis, may be regarded as a rare occurrence. Dr. Elliotson observes, that he does not recollect above twice seeing an abscess in the lung resulting from inflammation. Laennec says, that amongst several hundred dissections of pneumonic subjects, he did not meet with a collection of pus in an inflamed lung more than five or six times. The reason assigned is, that the disease is either cured by art or destroys life before it proceeds to the length of destroying the pulmonary tissue-that death takes place before the disease advances so far as for matter to be found in the lung in an abscess.

\section{DRY TAPPING}

TO THE EDITORS OF THE PROVINCIAL MEDICAL JOURNAL.

Gentlemen,-A case of tapping for dropsy, which was published in the "Provincial Medical Journal" for September 3, 1842, by Mr. Storrs, of Doncaster, reminded me of a case of apparent abscess situate just over the stomach and right lobe of the liver.

A middle-aged, married woman (who never was pregnant) had suffered under a long illness from dyspepsia, when a very hard swelling appeared in the above-named situation, which gradually increased to a large size, and became so extremely inconvenient as to confine her to her bed.

After poultices had becn applied some days, the swelling appeared to be a little reduced in size, and it felt softer, as if some of the matter had been absorbed and the sense of fluctuation had become more evident.

My partner (Mr. W. Mee) and I were not very positive about the propriety of plunging an abscess lancet into the swelling; however, as the constitution was disturbed, and as emaciation was the consequence, we determined upon making a puncture, having first told her friends that, although they must not be surprised if she died soon after the swelling was emptied, yet that the operation appeared to be the only means of saving her life.

After a lancet had been pushed in we found no matter!_but a great quantity of extremely offensive gas, which escaped with a loud hissing noise. The swelling gradually and entirely subsided; but, although the woman was pleased on feeling such immediate relief, and, although her friends expressed much satisfaction on the subsidence of the swelling, we (doubting whether or not the cyst communicated with the lungs, stomach, or gall-duct) left the cold poultice over a bit of lint, upon the orifice, to wait the issue. On calling the next day, the woman was sitting up below stairs, and she observed that "she got into bed expecting she had not long to live, but as the swelling was all gone away, she thought she might as well get up and attend to her household affairs.

She gradually recovered from that time, and is now living in good health, in Redford. I have twice tapped for dropsy, when the cyst has contained a jelly-like substance (in consistence), which would not pass through the canula, although I worked about a long probe through it; but on both occasions, after having let in air, a large quantity of fluid escaped during the next twenty-four hours. The size of the abdomen in that case was not satisfactorily reduced.

$$
\begin{aligned}
& \text { I am, Gentlemen, } \\
& \text { Yours very re spectfully, } \\
& \text { W. AlLison. }
\end{aligned}
$$

September 15, 1842. 